\title{
Serotypes, seasonal trends, and antibiotic resistance of non-typhoidal Salmonella from human patients in Guangdong Province, China, 2009-2012
}

Zhaoming Liang ${ }^{1,2}$, Bixia Ke², Xiaoling Deng ${ }^{2^{*}}$, Junhua Liang ${ }^{2}$, Lu Ran ${ }^{3}$, Lingling Lu², Dongmei He², Qiong Huang ${ }^{2}$, Changwen $\mathrm{Ke}^{2}$, Zhongjie $\mathrm{Li}^{3}$, Hongjie $\mathrm{Yu}^{3}$, John D Klena ${ }^{4,5}$ and Shuyu $\mathrm{Wu}^{4}$

\begin{abstract}
Background: Non-typhoidal Salmonella is a common cause of infectious diarrhea in humans. Antimicrobial-resistant Salmonella has become a global concern.

Methods: Using laboratory-based surveillance system for Salmonella from September 2009 to December 2012 in Guangdong Province of China. The clinical information and samples of diarrhea patients were collected, according to the surveillance case definition. The lab tests were followed by standardized protocols, including sample isolation, isolates confirmation, serotyping, and antimicrobial susceptibility testing (AST).

Results: A total of 1,826 Salmonella isolates were identified from40,572 patients in 28 hospitals in 11 prefectures. The isolates ratio was highest in autumn $(38.8 \%, 708 / 1826)$ and lowest in winter $(6.4 \%, 117 / 1826)$. Children aged $<5$ years were the group most affected by Salmonella in Guangdong Province accounting for $73 \%(1,329 / 1,826)$, of whom the infants ( $<1$ year) were $81.5 \%$ (1084/1329) especially. A total of 108 serotypes were identified among the isolates. $S$. Typhimurium represented the most common serotype followed by serotype 4,5,12:i:-.

S. Typhimurium was also the common serotype followed by $S$. Enteritidis among infants and children aged 1-3 years old. However, $S$. Enteritidis became the common serotype followed by S. Typhimurium among children aged $3-5$ and $>5$ years.

Resistance to at least one antimicrobial was found in $72 \%(1321 / 1,826)$ of the isolates. Resistance to at least three antimicrobials was found in $46 \%(850 / 1,826)$ of the isolates. Resistance to all 12 antimicrobials screened was observed in 8 isolates $(0.44 \%, 8 / 1,826)$. The resistant prevalence to quinolones including nalidixic acid and ciprofloxacin was 61.9\% (1131/1826), of which ciprofloxacin resistance rate was 8.05\% (147/1826). The prevalence resistance to all three cephalosporin antimicrobials (cefepime, cefotaxime, and caftazidime) in $<5 \mathrm{yr}$ age group was accounted for 90\% (89/99).
\end{abstract}

Conclusions: Additional data and more refined methods can improve future surveillance. The invasive Salmonella isolates should also be included to the antibiotic resistance surveillance for clinical care or public health.

\footnotetext{
*Correspondence: Dengxiaolinggd@aliyun.com

${ }^{2}$ Guangdong Provincial Centre for Disease Control and Prevention,

Guangzhou, Guangdong, China

Full list of author information is available at the end of the article
} 


\section{Background}

Foodborne disease is a global public health problem. Non-typhoidal Salmonella (NTS) remains one of the most commonly reported bacterial causes of foodborne infections diseases [1]. It is well-recognized that salmonellosis can be acquired by consumption of contaminated water, meat, eggs, or milk, or by contact with infected food animals and patients [2]. Manifestations of NTS included diarrheal and septicemia. Estimates suggest that globally 93.8 million people are infected by NTS, with 155,000 deaths each year [3]. In the United States, NTSis estimated to cause 1,027,561 illnesses, 19,336 hospitalizations and 378 deaths annually [4]. It has also been shown that children aged $<5$ years are a susceptible population to Salmonella infection [5]. However, similar data with respect to NTS infections is lacking in China [6]. NTS is typically self-limiting; antimicrobials are generally reserved for invasive infections [7]. Fluoroquinolones are among the antimicrobials commonly used to treat invasive salmonellosis among adults while cephalosporins are often employed for children [8,9]. However, several studies have shown a decreased susceptibility to ciprofloxacin as well as cephalosporins in Salmonella [9-12]. Furthermore, fluoroquinolone treatment failure in Salmonella infection has been reported in some countries [13-15]. Antimicrobial -resistant Salmonella has become a global concern $[16,17]$.

Currently, the national notifiable infectious diseases reporting system required diarrhea case reporting based on symptoms only. Laboratory-based surveillance is not commonly conducted at this time in China [18]. However, laboratory-based surveillance can provide information that permits identification of risk factors and control of infectious diseases, and implementation of NTS surveillance will allow for investigation of characteristics of Salmonella infections. Guangdong Province is a subtropical area in south China, with a season of high temperatures and humidity from March to October. Since 2009, laboratory-based surveillance for NTS has been established by the Guangdong Center for Disease Control and Prevention (GDCDC) [19]. In this report,epidemiological characteristics,including seasonal tendency, age distribution associated with serotype diversity, and antimicrobial resistance of NTS infections in Guangdong province are presented.

\section{Methods}

\section{Study design}

The surveillance case definition was defined as a person who presented with three or more loose stools within 24 hours and whose diarrhea was associated with one or more of the following symptoms:fever, vomiting, or abdominal pain. Data from September 2009 to December 2012 collected from 28 hospitals in 11 prefectures in
Guangdong Province were included in this analysis. Among the 28 hospitals, five were pediatric facilities and the remaining were general hospitals. Epidemiologic information about the patients such as sex, age and consult date were recorded. Spring was defined from March to May, summer from June to August, autumn from September to November, winter from December to February. A standardized protocol was distributed to the sentinel hospitals to guide the collection and processing of stool samples. Clinical laboratories were responsible for Salmonella isolation and suspected isolates were stored in semi-solid agar and submitted to GDCDC within one week of collection for confirmation, serotyping, and Antimicrobial susceptibility testing.

The research involving human subjects have been approved with Guangdong medical ethics comply with the Helsinki Declaration. All the participants have approved the study.

\section{Salmonella serotyping}

NTS isolates were confirmed using API 20E test strips (bioMerieux, Marcy L'Etoile, France) before serotyping. O and $\mathrm{H}$ antigens were characterized using commercial antiserum (S\&A Reagents Lab, Bangkok, Thailand) and the serotypes were identified according to Kauffmann-White Scheme [20].

\section{Antimicrobial susceptibility testing (AST)}

The antimicrobial susceptibility of the isolates was determined according to the guidelines of the Clinical and Laboratory Standards Institute (CLSI) [21]. Disk diffusion assays were performed on Muller-Hinton agar with antibiotic impregnated disks. The tested antibiotics included streptomycin $10 \mu \mathrm{g}(\mathrm{S})$, gentamicin $10 \mu \mathrm{g}(\mathrm{G})$, ceftazidime $30 \mu \mathrm{g}(\mathrm{Caz})$, cefotaxime $30 \mu \mathrm{g}$ (Ctx), cefepime $30 \mu \mathrm{g}$ (Fep), ampicillin $10 \mu \mathrm{g}(\mathrm{A})$, nalidixic acid $30 \mu \mathrm{g}(\mathrm{Nal})$, ciproflaxin $5 \mu \mathrm{g}(\mathrm{Cp})$, tetracycline $30 \mu \mathrm{g}(\mathrm{T})$, chloramphenicol $30 \mu \mathrm{g}(\mathrm{C})$, sulfamethoxazole $300 \mu \mathrm{g}(\mathrm{Su})$, and trimethoprim $5 \mu \mathrm{g}(\mathrm{Tm})$. The diameter of the inhibition zone was interpreted as resistant, intermediate or susceptible according to CLSI guidelines [21]. Escherichia coli ATCC 25922 was used as quality control organism. Ampicillin, trimethoprim, sulfamethoxazole, cefotaxime, ceftazidime, cefpime, ciprofloxacin and gentamicin were defined as clinically important antimicrobials [22]. Multidrug resistance (MDR) was identified as resistance to three or more than three classes of antimicrobials. ACSSuT pattern was defined as resistance to ampicillin, chloramphenicol [6]. Streptomycin, sulfamethoxazole, tetracycline.

\section{Data analysis}

Data were analyzed using SPSS version 13.0 (SPSS Institute, city, state, USA). Chi-squared analysis was performed to test the statistical association between 
serotypes and age distribution, and to compare the percentage of multi-drug resistant isolates in a given serotype. A $P$-value $<0.05$ was considered statistically significant.

\section{Results}

Isolation rate and serotypes

Stool samples were collected from 40,572 patients with diarrhea in Guangdong Province between September 2009 and December 2012, and1,826 NTS isolates were recovered. The isolation rate of NTS was 4.5\%. A total of 108 serotypes were identified among the isolates. Ten serotypes accounted for $80 \%(1,462 / 1,826)$ of the NTS isolates in this study, including $S$. Typhimurium $(\mathrm{n}=550 ; 30 \%), S$. serotype 4,5,12:i:- $(\mathrm{n}=254 ; 14 \%), S$. Enteritidis $(\mathrm{n}=245 ; 13 \%)$, $S$. Stanley $(\mathrm{n}=189 ; 10 \%), S$. Derby $(\mathrm{n}=48 ; 2.6 \%), S$. Rissen $(\mathrm{n}=43 ; 2.4 \%), S$. Weltevreden $(\mathrm{n}=38 ; 2.1 \%), S$. Infantis $(\mathrm{n}=29 ; 1.6 \%), S$. Thompson $(\mathrm{n}=26 ; 1.4 \%), S$. Albany $(\mathrm{n}=20 ; 1.1 \%)$ and $S$. Agona $(\mathrm{n}=20 ; 1.1 \%)$.

\section{Seasonal, sex and age distribution}

The isolation rate in spring was 3.5\% (261/7,488), 6.4\% $(680 / 10594)$ in summer, $5.4 \%(708 / 13,039)$ in autumn and $1.9 \%(177 / 9,451)$ in winter. The isolation rate was highest in September $2011(10 \%, 83 / 817)$ and lowest in December, 2009 (0.8\%, 7/861). Infections occurring in autumn accounted for $39 \%$ of all NTS cases followed by $37 \%$ in summer.
There were 1,031 males and 725 females infected with NTS; the sex of 70 cases was unknown. The overall male/female ratio was 1.4:1. The patients ranged in age from 20 days to 96 years (115 cases unknown). The median age was 1 year. Children $<5$ years accounted for $73 \%$ $(1,329 / 1,826)$ of NTS cases. Of the 1,329 patients,1,084 were infants $<1$ year. Among infants, $S$. Typhimurium was the most common serotype causing 37\% (404/ $1,084)$ of infections followed by $S$. serotype 4,5,12:i:$(17 \%, 189 / 1,084)$ and S. Stanley $(11 \%, 120 / 1084)$. S. Enteritidis accounted for only $6.8 \%(74 / 1,084)$. Among children aged1-2 and 2-3 years, $S$. Typhimurium was the highest, followed by $S$. Enteritidis, $S$. serotype 4,5,12:i:- and S. Stanley. However, among children aged $3-4,4-5$, and $>5$ years, the proportion infected with $S$. Enteritidis became the highest compared to other serotypes, and $S$. Typhimurium became the second common serotype (Table 1).

\section{Antimicrobial resistance}

A total of 168 (9.2\%) of the 1,826 NTS isolates were susceptible to all 12 antimicrobials (9.2\%). S. Weltevreden showed a high rate of pan-susceptibility to antimicrobials (47\%, 18/ $38)$, followed by $S$. Stanley $(31 \%, 58 / 189)$. However, very few $S$. Typhimurium $(1.5 \% ; 8 / 550)$ and $S$. serotype 4,5,12:i:$(0.8 \%, 2 / 254)$ isolates were pan-susceptible. The Salmonella isolates obtained in this study showed high prevalence of resistance to the tested antimicrobials (Table 2). Overall

Table 1 Descriptive data of Salmonella infections by serotype in diarrhea patients in Guangdong province in 2009 - 2012

\begin{tabular}{|c|c|c|c|c|c|c|c|c|c|c|c|c|c|}
\hline Variable & $\begin{array}{l}\text { Typhimurium } \\
\text { N (\%) }\end{array}$ & $\begin{array}{l}\text { 4,5,12:i:- } \\
N(\%)\end{array}$ & $\begin{array}{l}\text { Enteritidis } \\
\text { N (\%) }\end{array}$ & $\begin{array}{l}\text { Stanley } \\
\text { N (\%) }\end{array}$ & $\begin{array}{l}\text { Derby } \\
\text { N (\%) }\end{array}$ & $\begin{array}{l}\text { Rissen } \\
\text { N (\%) }\end{array}$ & $\begin{array}{l}\text { Weltevreden } \\
\mathrm{N}(\%)\end{array}$ & $\begin{array}{l}\text { Infantis } \\
\text { N (\%) }\end{array}$ & $\begin{array}{l}\text { Thompson } \\
\text { N (\%) }\end{array}$ & $\begin{array}{l}\text { Albany } \\
\text { N (\%) }\end{array}$ & $\begin{array}{l}\text { Agona } \\
\text { N (\%) }\end{array}$ & $\begin{array}{l}\text { Other } \\
\mathrm{N}(\%)\end{array}$ & $\begin{array}{l}\text { Overall } \\
\mathrm{N}(\%)\end{array}$ \\
\hline \multicolumn{14}{|l|}{ Season } \\
\hline Spring & $100(38)$ & 35 (13) & $41(16)$ & $23(8.8)$ & $6(2.3)$ & $4(1.5)$ & $7(2.7)$ & $0(0.0)$ & $6(2.3)$ & $1(0.4)$ & $2(0.8)$ & 36 (14) & $261(100)$ \\
\hline Summer & $184(27)$ & $111(16)$ & 88 (13) & 59 (8.7) & $23(3.4)$ & $23(3.4)$ & $10(1.5)$ & $10(1.5)$ & $5(0.7)$ & $10(1.5)$ & $12(1.8)$ & $145(21)$ & $680(100)$ \\
\hline Autumn & $213(30)$ & 87 (12) & 88 (12) & 96 (14) & $14(2.0)$ & 13 (1.8) & $14(2.0)$ & $18(2.5)$ & 11 (1.6) & $9(1.3)$ & $5(0.7)$ & $140(20)$ & 708 (100) \\
\hline Winter & $53(30)$ & $21(12)$ & 28 (16) & $11(6.2)$ & $5(2.8)$ & $3(1.7)$ & $7(4.0)$ & $1(0.6)$ & $4(2.3)$ & $0(0.0)$ & $1(0.6)$ & $43(24)$ & 117 (100) \\
\hline \multicolumn{14}{|l|}{ Sex } \\
\hline Male & $324(31)$ & $151(15)$ & $125(12)$ & $102(10)$ & $27(2.6)$ & $24(2.3)$ & $25(2.4)$ & 16 (1.6) & $15(1.5)$ & $8(0.8)$ & $12(1.2)$ & $202(20)$ & 1031 (100) \\
\hline Female & $200(28)$ & 98 (14) & 109 (15) & 81 (11) & $20(2.8)$ & $16(2.2)$ & $12(1.7)$ & $11(1.5)$ & $8(1.1)$ & $12(1.7)$ & $8(1.1)$ & $150(21)$ & 725 (100) \\
\hline Unknown & $26(37)$ & $5(7.1)$ & 11 (16) & $6(8.6)$ & $1(1.4)$ & $3(4.3)$ & $1(1.4)$ & $2(2.9)$ & $3(4.3)$ & $0(0.0)$ & $0(0.0)$ & $12(17)$ & 70 (100) \\
\hline \multicolumn{14}{|l|}{ Age } \\
\hline$\leq 1$ & 404 (37) & $189(17)$ & $74(6.8)$ & $120(11)$ & $24(2.2)$ & $26(2.4)$ & $13(1.2)$ & $18(1.7)$ & $13(1.2)$ & $10(0.9)$ & $10(0.9)$ & $183(17)$ & 1084 (100) \\
\hline$\sim 2$ & $41(21)$ & 32 (17) & 34 (18) & 35 (18) & $5(2.6)$ & $2(1.0)$ & $0(0.0)$ & $2(1.0)$ & $5(2.6)$ & $3(1.6)$ & $4(2.1)$ & 29 (15) & $192(100)$ \\
\hline$\sim 3$ & $24(28)$ & $10(9.1)$ & $24(22)$ & $7(6.4)$ & $4(3.6)$ & $1(0.9)$ & $7(6.4)$ & $3(2.7)$ & $1(0.9)$ & $0(0.0)$ & $2(1.8)$ & $27(24)$ & $110(100)$ \\
\hline 〜) & $12(17)$ & $3(4.3)$ & $22(32)$ & $6(8.7)$ & $1(1.4)$ & $1(1.4)$ & $4(5.8)$ & $0(0.0)$ & $2(2.9)$ & $3(4.3)$ & $1(1.4)$ & $14(20)$ & $69(100)$ \\
\hline$\sim 5$ & 9 (19) & $4(8.5)$ & $18(38)$ & $2(4.3)$ & $1(2.1)$ & $0(0.0)$ & $1(2.1)$ & $1(2.1)$ & $0(0.0)$ & $1(2.1)$ & $0(0.0)$ & $10(21)$ & 47 (100) \\
\hline$\geq 5$ & $20(9.6)$ & 7 (3.3) & $54(26)$ & $11(5.3)$ & $10(4.8)$ & $9(4.3)$ & $12(5.7)$ & $3(1.4)$ & $2(1.0)$ & $3(1.4)$ & $3(1.4)$ & 75 (36) & 209 (100) \\
\hline Unknown & $40(35)$ & $9(7.8)$ & 19 (16) & $8(7.0)$ & $3(2.6)$ & $4(3.5)$ & $1(0.9)$ & $2(1.7)$ & $3(2.6)$ & $0(0.0)$ & $0(0.0)$ & $26(23)$ & 115 (100) \\
\hline Overall & $550(30)$ & $254(14)$ & $245(13)$ & $189(10)$ & $48(2.6)$ & $43(2.4)$ & $38(2.1)$ & 29 (1.6) & $26(1.4)$ & $20(1.1)$ & $20(1.1)$ & $364(20)$ & $1826(100)$ \\
\hline
\end{tabular}


Table 2 Antimicrobial resistance of Salmonella serotypes in Guangdong province in 2009 - 2012

\begin{tabular}{|c|c|c|c|c|c|c|c|c|c|c|c|c|}
\hline \multirow[t]{3}{*}{ Antimicrobial } & \multicolumn{2}{|c|}{ Typhimurium $(n=550)$} & \multicolumn{2}{|c|}{ 4,5,12:i:- $(n=254)$} & \multicolumn{2}{|c|}{ Enteritidis $(n=245)$} & \multicolumn{2}{|c|}{ Stanley $(n=189)$} & \multicolumn{2}{|c|}{ Derby $(n=48)$} & \multicolumn{2}{|c|}{ Rissen $(n=43)$} \\
\hline & $<5 \mathrm{yrs}$ & $\geq 5 \mathrm{yrs}$ & $<5 \mathrm{yrs}$ & $\geq 5 \mathrm{yrs}$ & $<5 \mathrm{yrs}$ & $\geq 5 \mathrm{yrs}$ & $<5 \mathrm{yrs}$ & $\geq 5 \mathrm{yrs}$ & $<5$ yrs & $\geq 5 \mathrm{yrs}$ & $<5$ yrs & $\geq 5 \mathrm{yrs}$ \\
\hline & N (\%) & N (\%) & N (\%) & N (\%) & N (\%) & N (\%) & N (\%) & N (\%) & N (\%) & N (\%) & N (\%) & N (\%) \\
\hline \multicolumn{13}{|l|}{ Aminoglycosides } \\
\hline Getamicin & $302(66)$ & $32(65)$ & $131(57)$ & $10(71)$ & $14(12)$ & $13(12)$ & $11(6.9)$ & $1(4.8)$ & $8(27)$ & $6(40)$ & $3(11)$ & $3(27)$ \\
\hline Streptomycin & $335(73)$ & $36(74)$ & $154(67)$ & $9(64)$ & $44(36)$ & $41(39)$ & $22(14)$ & $1(4.8)$ & $10(33)$ & $7(47)$ & $13(46)$ & $6(54)$ \\
\hline \multicolumn{13}{|l|}{ Cephalosporins } \\
\hline Cefepime & $71(15)$ & $3(6.1)$ & $29(13)$ & $1(7.1)$ & $14(12)$ & $6(5.7)$ & $9(5.6)$ & $0(0.0)$ & $3(10)$ & $0(0.0)$ & $5(18)$ & $0(0.0)$ \\
\hline Cefotaxime & $67(14)$ & $5(10)$ & $30(13)$ & $0(0.0)$ & $12(10)$ & $5(4.8)$ & $10(6.3)$ & $1(4.8)$ & $3(10)$ & $0(0.0)$ & $5(18)$ & $0(0.0)$ \\
\hline Caftazidime & $45(9.8)$ & $2(4.1)$ & $18(7.8)$ & $0(0.0)$ & $7(5.8)$ & $5(4.8)$ & $8(5.0)$ & $1(4.8)$ & $1(3.3)$ & $0(0.0)$ & $3(11)$ & $0(0.0)$ \\
\hline \multicolumn{13}{|l|}{ Penicillins } \\
\hline Ampicillin & 412 (89) & $35(71)$ & $215(93)$ & $11(79)$ & $68(56)$ & $59(56)$ & $18(11)$ & $3(14)$ & $12(40)$ & $6(40)$ & $21(75)$ & $8(73)$ \\
\hline \multicolumn{13}{|l|}{ Quinolones } \\
\hline Nalidixic acid & $383(83)$ & $37(76)$ & $167(73)$ & $13(93)$ & $94(78)$ & $89(85)$ & $17(11)$ & $1(4.8)$ & $11(37)$ & $7(47)$ & $3(11)$ & $1(9.1)$ \\
\hline Ciprofloxacin & $56(12)$ & $5(10)$ & $27(12)$ & $1(7.1)$ & $7(5.8)$ & $7(6.7)$ & $8(5.0)$ & $0(0.0)$ & $1(3.3)$ & $3(20)$ & $1(3.6)$ & $0(0.0)$ \\
\hline \multicolumn{13}{|l|}{ Tetracyclines } \\
\hline Tetracycline & $402(87)$ & $34(69)$ & $214(93)$ & $13(93)$ & $32(26)$ & $28(27)$ & $22(14)$ & $1(4.8)$ & $21(70)$ & $8(53)$ & $25(89)$ & $8(73)$ \\
\hline \multicolumn{13}{|l|}{ Amphenicols } \\
\hline Chloramphenicol & $335(73)$ & $28(57)$ & $154(67)$ & $9(64)$ & $5(4.1)$ & $5(4.8)$ & $8(5.0)$ & $2(9.5)$ & $9(30)$ & $6(40)$ & $4(14)$ & $1(9.1)$ \\
\hline \multicolumn{13}{|l|}{ Sulfonamides } \\
\hline Sulfamethoxazole & $398(86)$ & $35(71)$ & $206(89)$ & $12(86)$ & $60(50)$ & $53(50)$ & $31(19)$ & $3(14)$ & $15(50)$ & $7(47)$ & $21(75)$ & $5(46)$ \\
\hline Trimethoprim & $298(65)$ & $27(55)$ & $117(51)$ & $8(57)$ & $16(13)$ & $10(9.5)$ & $10(6.3)$ & $2(9.5)$ & $8(27)$ & $6(40)$ & $24(86)$ & $9(82)$ \\
\hline \multicolumn{13}{|l|}{ Multi-resistance } \\
\hline$\geq 3$ antimicrobials & $356(77)$ & $31(63)$ & $188(81)$ & $9(64)$ & $65(54)$ & $73(70)$ & $49(31)$ & $7(33)$ & $15(50)$ & $6(40)$ & $22(79)$ & $8(73)$ \\
\hline \multirow[t]{4}{*}{ ACSSUT* } & $244(53)$ & $25(51)$ & $92(40)$ & $6(43)$ & $3(2.5)$ & $3(2.9)$ & $2(1.3)$ & $1(4.8)$ & $6(20)$ & $4(27)$ & $3(11)$ & $1(9.1)$ \\
\hline & $\begin{array}{l}\text { Weltevreden } \\
(n=38)\end{array}$ & $\begin{array}{l}\text { Infantis } \\
(n=29)\end{array}$ & $\begin{array}{l}\text { Thompson } \\
(n=26)\end{array}$ & $\begin{array}{l}\text { Albany } \\
(n=20)\end{array}$ & $\begin{array}{l}\text { Agona } \\
(n=20)\end{array}$ & $\begin{array}{l}\text { Other } \\
(n=364)\end{array}$ & $\begin{array}{l}\text { Weltevreden } \\
(\mathrm{n}=38)\end{array}$ & $\begin{array}{l}\text { Infantis } \\
(n=29)\end{array}$ & $\begin{array}{l}\text { Thompson } \\
(n=26)\end{array}$ & $\begin{array}{l}\text { Albany } \\
(n=20)\end{array}$ & $\begin{array}{l}\text { Agona } \\
(n=20)\end{array}$ & $\begin{array}{l}\text { Other } \\
(\mathrm{n}=364)\end{array}$ \\
\hline & $<5$ yrs & $\geq 5 \mathrm{yrs}$ & $<5 \mathrm{yrs}$ & $\geq 5$ yrs & $<5 \mathrm{yrs}$ & $\geq 5$ yrs & $<5 \mathrm{yrs}$ & $\geq 5$ yrs & $<5$ yrs & $\geq 5$ yrs & $<5$ yrs & $\geq 5 \mathrm{yrs}$ \\
\hline & N (\%) & N (\%) & $\mathrm{N}(\%)$ & N (\%) & N (\%) & N (\%) & N (\%) & N (\%) & N (\%) & N (\%) & N (\%) & N (\%) \\
\hline \multicolumn{13}{|l|}{ Aminoglycosides } \\
\hline Getamicin & $3(23)$ & $1(4.2)$ & $2(10)$ & $2(29)$ & $2(10)$ & $1(25)$ & $3(27)$ & $1(11)$ & $4(29)$ & $1(17)$ & $37(17)$ & $19(16)$ \\
\hline Streptomycin & $3(23)$ & $3(12)$ & $2(10)$ & $2(29)$ & $12(63)$ & $3(75)$ & $3(27)$ & $3(33)$ & $4(29)$ & $2(33)$ & $61(28)$ & $37(32)$ \\
\hline \multicolumn{13}{|l|}{ Cephalosporins } \\
\hline Cefepime & $3(23)$ & $1(4.2)$ & $2(10)$ & $2(29)$ & $1(5.3)$ & $1(25)$ & $4(36)$ & $1(11)$ & $3(21)$ & $1(17)$ & $20(9.0)$ & $19(16)$ \\
\hline
\end{tabular}


Table 2 Antimicrobial resistance of Salmonella serotypes in Guangdong province in 2009 - 2012 (Continued)

\begin{tabular}{|c|c|c|c|c|c|c|c|c|c|c|c|c|}
\hline Cefotaxime & $2(15)$ & $0(0.0)$ & $3(15)$ & $0(0.0)$ & $5(26)$ & $1(25)$ & $4(36)$ & $0(0.0)$ & $2(14)$ & $0(0.0)$ & $0(0.0)$ & $9(7.7)$ \\
\hline Caftazidime & $2(15)$ & $0(0.0)$ & $2(10)$ & $0(0.0)$ & $6(32)$ & $1(25)$ & $3(27)$ & $0(0.0)$ & $2(14)$ & $1(17)$ & $16(7.2)$ & $7(6.0)$ \\
\hline \multicolumn{13}{|l|}{ Penicillins } \\
\hline Ampicillin & $1(7.7)$ & $2(8.3)$ & $16(80)$ & $6(86)$ & $12(63)$ & $1(25)$ & $11(100)$ & $9(100)$ & $3(21)$ & $2(33)$ & $79(36)$ & $33(28)$ \\
\hline \multicolumn{13}{|l|}{ Quinolones } \\
\hline Nalidixic acid & $2(15)$ & $2(8.3)$ & $16(80)$ & $5(71)$ & $5(26)$ & $2(50)$ & $9(82)$ & $9(100)$ & $4(29)$ & $0(0.0)$ & $71(32)$ & $36(31)$ \\
\hline Ciprofloxacin & $0(0.0)$ & $1(4.2)$ & $0(0.0)$ & $0(0.0)$ & $0(0.0)$ & $2(50)$ & $1(9.1)$ & $0(0.0)$ & $3(21)$ & $1(17)$ & $19(8.6)$ & $4(3.4)$ \\
\hline \multicolumn{13}{|l|}{ Tetracyclines } \\
\hline Tetracycline & $2(15)$ & $4(17)$ & $11(55)$ & $6(86)$ & $13(68)$ & $2(50)$ & $9(82)$ & $9(100)$ & $6(43)$ & $2(33)$ & $82(37)$ & $52(44)$ \\
\hline \multicolumn{13}{|l|}{ Amphenicols } \\
\hline Chloramphenicol & $0(0.0)$ & $2(8.3)$ & $12(60)$ & $6(86)$ & $7(37)$ & $2(50)$ & $9(82)$ & $9(100)$ & $3(21)$ & $2(33)$ & $45(20)$ & $16(14)$ \\
\hline \multicolumn{13}{|l|}{ Sulfonamides } \\
\hline Sulfamethoxazole & $3(23)$ & $5(21)$ & $15(75)$ & $6(86)$ & $14(74)$ & $2(50)$ & $10(91)$ & $9(100)$ & $3(21)$ & $1(17)$ & $79(36)$ & $50(43)$ \\
\hline Trimethoprim & $1(7.7)$ & $3(12)$ & $13(65)$ & $4(57)$ & $8(42)$ & $2(50)$ & $9(82)$ & $9(100)$ & $2(14)$ & $1(17)$ & $51(23)$ & $37(32)$ \\
\hline \multicolumn{13}{|l|}{ Multi-resistance } \\
\hline$\geq 3$ antimicrobials & $4(31)$ & $12(50)$ & $13(65)$ & $3(43)$ & $16(84)$ & $4(100)$ & $9(82)$ & $8(89)$ & $5(36)$ & $4(67)$ & $106(48)$ & $62(53)$ \\
\hline ACSSUT* & $0(0.0)$ & $0(0.0)$ & $1(5.0)$ & $2(29)$ & $6(32)$ & $1(25)$ & $3(27)$ & $3(33)$ & $1(7.1)$ & $1(17)$ & $25(11)$ & $12(10)$ \\
\hline
\end{tabular}

*Resistance to ampicillin, chloramphenicol, streptomycin, sulfamethoxazole, tetracycline. 
NTS isolates from children aged $<5$ years showed a higher prevalence of antimicrobial resistance than those from patients $>5$ years, and included resistance to cephalosporins and quinolones.

Resistance to cefepime, cefotaxime, and ceftazidime was found in $10 \%, 11 \%$, and $7.4 \%$ of isolates, respectively. Resistance to all three cephalosporin antimicrobials was seen in 99 isolates, of which patients $<5$ years accounted for $90 \%$ (89/99) and $S$. Typhimurium accounted for $46 \%$ (45/99). Among children $<5$ years, isolates resistant to cefepime, cefotaxime and caftazidime accounted for $12 \%, 12 \%$ and $8.5 \%$ while the resistance rate in patients $\geq 5$ years was $4.7 \%, 5.5 \%$, and $4.5 \%$, respectively. The resistance rate to cefepime $(P<0.01)$ and cefotaxime $(P<0.01)$ was higher in children $<5$ years than in patients $>5$ years but no difference was seen in the resistance rate to ceftazidime $(P>0.05)$.

A high prevalence of nalidixic acid resistance was observed $(58 \% ; 1,062 / 1,826)$ in the NTS isolates. A total of 155 isolates $(8.5 \%, 155 / 1826)$ were resistant to ciprofloxacin. The overall resistance rate to ciprofloxacin increased from $2.4 \%$ in 2009 to $12 \%$ in 2012 (Figure 1). S. Typhimurium, $S$. serotype 4,5,12:i:- and S. Enteritidis accounted for 843 out of the 1,062 resistant isolates (79\%). Isolates of $S$. Typhimurium made up $41 \%(64 / 155)$ of the ciprofloxacin-resistant isolates, followed by $S$. serotype4,5,12:i:- (19\%, 30/155).
A rate of $63 \%(1156 / 1826)$ MDR was observed in NTS isolates in this study, with $S$. Typhimurium isolates accounting for $36 \%(418 / 1156)$ followed by $S$. serotype 4,5,12:i:- (18\%, 206/1156) and S. Enteritidis (13\%, 150/ 1156). Resistance to at least one antimicrobial was found in $72 \%(1321 / 1,826)$ of the isolates; resistance to at least three antimicrobials was found in $46 \%(850 / 1,826)$ of the isolates. Resistance to all 12 antimicrobials screened as part of this surveillance project was observed in 8 isolates $(6 \mathrm{~S}$. Typhimurium, a single $S$. serotype 4,5,12:i:- and a single Duisburg). In this study, 473NTS isolates showed the ACSSuT resistance pattern. S. Typhimurium accounted for $60 \%$ (284/473) followed by $S$. serotype 4,5,12:i:- (21\%, 101/473). This resistance pattern was significantly associated with infection by $S$. Typhimurium and $S$. serotype 4,5,12:i:-compared to other serotypes $(P<0.01)$. Childrenaged $<5$ years accounted for $27 \%(412 / 1,502)$ of NTS isolates with the ACSSuT pattern, while there were only $16 \%(33 / 209)$ patients aged $\geq 5$ yearshad this pattern $(P<0.01)$.

\section{Discussion}

In this study, we report epidemiologic characteristics of NTS infections in Guangdong Province from 2009 to 2012. An increase in the NTS isolation rate was observed beginning at $3.4 \%$ in $2009,3.5 \%$ in $2010,4.4 \%$ in 2011 and $5.1 \%$ in 2012. Since the surveillance was conducted, several training courses were designed by

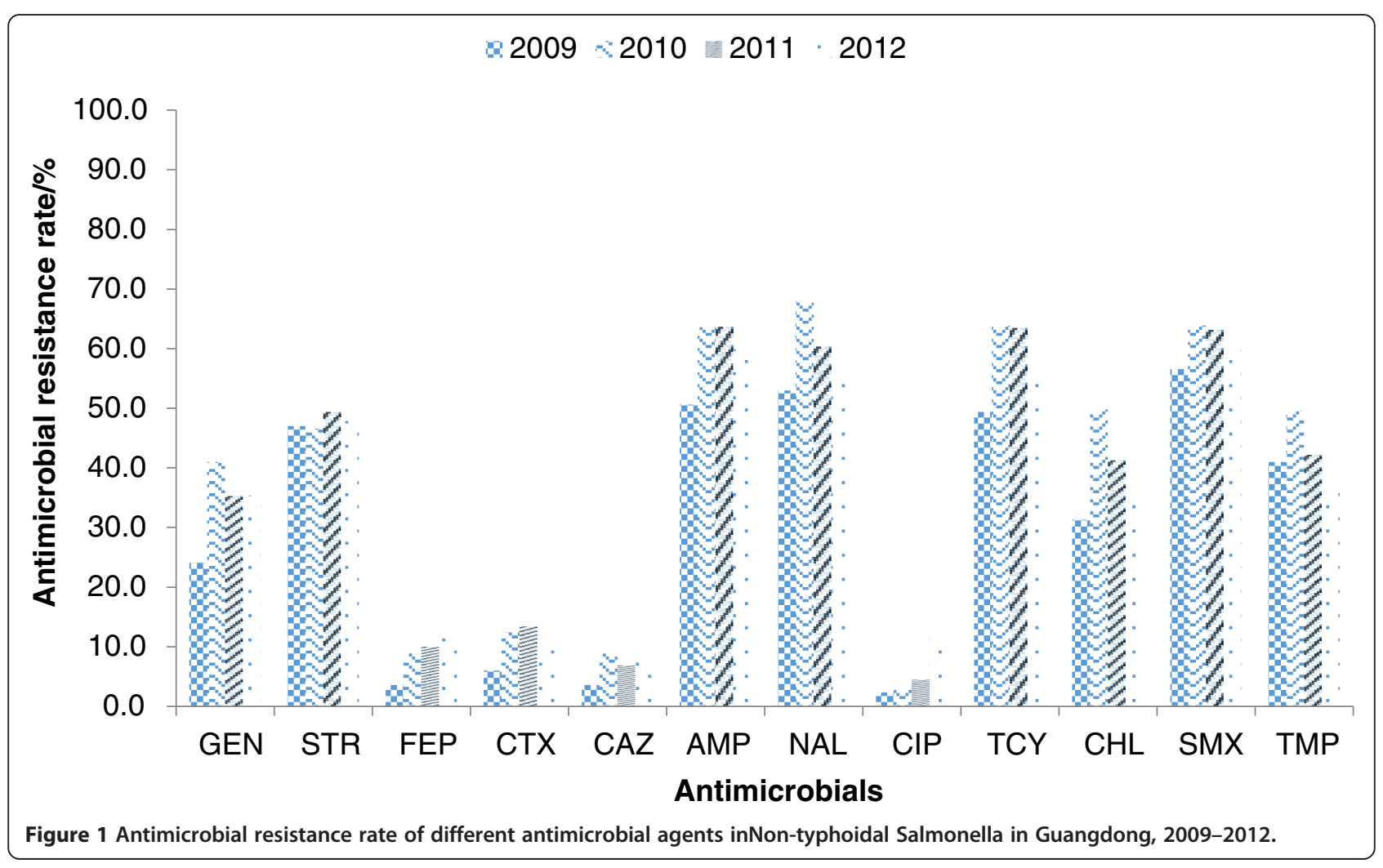


GDCDC for clinicians and lab staff to improve the capacity of detecting and reporting food-borne disease cases in Guangdong Province [23].

Our study showed that children aged $<5$ years were the group most affected by NTS in Guangdong Province. In a previous study, children $<5$ years were shown to be at risk for NTS infections [24]. In the United States, the NTS isolation rate was highest in patients aged $<1$ year [25]. In our study, children aged $<5$ years accounted for $73 \%$ of the overall NTS infections. Even in general hospitals, children $<5$ years accounted for $65 \%$ of the infections. This rateis were higher than that in a previous national report, which NTS isolated from eight provinces were associated with diarrhea in $34 \%$ of patients $<5$ years in China [6]. In other countries, a high prevalence of NTS infection in children $<5$ years has also been reported [26,27]. Future epidemiological investigations about risk factors should be conducted to determine why children $<5$ years, especially infants $(<1$ year) in Guangdong have become the majority of infections for disease control and prevention.

Salmonella serotype 4,5,12:i:- is considered a monophasic variant of serotype Typhimurium with similar antigenic and genotypic characteristics. In our study, the percentage of $S$. serotype 4,5,12:i:- increased from 3.6\% in 2009 to $20 \%$ in 2011 and down to $15 \%$ in 2012, becoming one of the most common Salmonella serotypes in Guangdong. In Europe,S. serotype 4,5,12:i:-showed a marked increase in foodborne infections with an association in pig meat [28]. This serotype has also been recognized as an emerging cause of infection in other countries in the world [29].

Increasing antimicrobial resistance was observed in this study, especially to the conventional first-line agents, such as $\beta$-lactam antibiotics and quinolones. Regionally, NTS isolates recovered in Malaysia also showed high resistance rates to tetracycline (70\%), sulfonamides (57\%), and streptomycin (53\%) but lower rates to ampicillin (30\%),nalidicix acid (28\%) and chloramphenicol (21\%) than in China [30]. Resistance rates in the United States to ampicillin, chloramphenicol, and nalidixicacid were even lower, $20 \%, 11 \%$, and $2.7 \%$, respectively [31]. Drug resistance in China is likely multifaceted, with resistant isolates selected after environmental, clinical and veterinary antibiotic exposures. Further investigations exploring the emergence of resistant NTS isolates are required to control this public health problem.

Extended-spectrum cephalosporins and fluoroquinolones have been recommended for treatment of diarrhea resulting from a NTS infection [32,33], although a recent review suggests that there is little added benefit for treatment in an otherwise healthy individual [33]. It is noted that the prevalence of cephalosporins resistance was higher in children aged $<5$ years than in patients aged $\geq 5$ years. Also the majority of isolates resistant to all three cephalosporins were from children aged $<5$ years, suggesting more attention should be given to the severe resistance of Salmonella infections in young children. High resistance will increase the diarrhea burden among children [34]. In the United States, $4.1 \%$ of the isolates displayed decreased susceptibility to either ceftriaxone or ceftiofur in 2005 and 2006, while it was only $1 \%$ in 1996-1998 [9]. An increase in the number of isolates displaying decreased susceptibility may have an impact on clinical treatment and may lead to treatment failure as cephalosporins are the primary choice for children.

Reduced susceptibility to ciprofloxacin is a current trend in NTS isolates globally. The MIC of NTS isolates from Asian countries rose from 0.125 to $1 \mu \mathrm{g} / \mathrm{ml}$ during 2003 to 2005 [12]. Nalidixic acid susceptibility testing has been recommended by CLSI before using ciprofloxacin for treatment, as isolates resistant to nalidixic acid are probably resistant to ciprofloxacin [35].

This study had some limitations. First, selection of the sentinel hospitals was based on convenience but not the catchment size of the local population. Ten of the 28 hospitals involved were located in the capital city, Guangzhou, while only two or three hospitals included from the other cities in Guangdong. Future expansion of NTS surveillance in Guangdong should incorporate hospitals based on the coverage of the population in each catchment area. Second, only a minority of all patients with diarrhea have stool specimens collected for culture, as stool culture is not required in China for diarrheal patients. Finally, the Salmonella isolation rate was not very high, possibly because of previous antibiotic use or laboratory testing sensitivity. In the future, increasing the rate of specimen collection, the rate of isolation, the number of facilities in surveillance, and improving the representativeness of the surveillance system will help to improve our understanding of foodborne disease incidence and increase sensitivity for outbreak detection in Guangdong China.

\section{Conclusion}

In conclusion, $S$. Typhimurium represented the most common serotype followed by serotype 4,5,12:i:- in Guangdong Province in China. Children aged $<5$ years were the group most affected by Salmonella in Guangdong Province. A high prevalence of antimicrobial resistance, including resistance to ciprofloxacin and cephalosporins, was observed among the isolates, especially from children aged $<5$ years. Improved characterization of Salmonella infections would facilitate risk assessment of Salmonella infections. Moreover, making the antimicrobial susceptibility testing of Salmonella isolates by clinical laboratories routinely would allow clinicians to choose appropriate antimicrobials for treatment of infectious 
diarrhea. However, additional data and more refined methods can improve future surveillance. The invasive Salmonella isolates should also be included to the antibiotic resistance surveillance for clinical care or public health.

\section{Limitation}

It was a limitation that this study only included isolates from stool but not from blood and etc. Due to the statistic we have collected, we only can provide clinical correlates with these isolates about whether the cases are outpatients or inpatients. Since Fluoroquinolones are commonly used to treat serious diarrheal for adults while cephalosporins are often employed for children in China, we compared the resistance of cefepime, nalidixic acid, ciprofloxacin in inpatient cases is more severe than in outpatient cases $(\mathrm{P}<0.01)$, respectively. If we assumed inpatient cases are more severe than outpatient cases, it seems like the high antibiotic resistance prevalence is associated with serious clinical diseases. However, more information should be collected and analyzed in the future.

\section{Consent}

Written informed consent was obtained from the patient's guardian/parent/next of kin for the publication of this report and any accompanying images.

\section{Abbreviations}

NTS: Non-typhoidalSalmonella; GDCDC: Guangdong center for disease control and prevention; AST: Antimicrobial susceptibility testing; CLSI: Clinical and laboratory standards institute; MDR: Multi-drug resistance; ACSSUT: Resistance to ampicillin, chloramphenicol, streptomycin, sulfamethoxazole, tetracycline.

\section{Competing interests}

The authors declare that they have no competing interests.

\section{Authors' contributions}

ZL carried out the salmonella serotyping studies and drafted the manuscript. $B K, D H, C K$ carried out the strain isolation, and identification. JL, $L R, L L, Q H$, $Z L, H Y, J D K$, SW participated in the design of the study and performed the statistical analysis. XD conceived of the study, and participated in its design and coordination, and revised the paper. All authors read and approved the final manuscript.

\section{Acknowledgements}

This study was supported by the China-U.S. Collaborative program on Emerging and Re-Emerging Infectious Diseases and the National Major Projects of Major Infectious Disease Control and Prevention, the Ministry of Science and Technology of the People's Republic of China (grant number:2012ZX10004213-004).

The findings and conclusions in this report are those of the authors and do not necessarily represent the official position of the Centers for Disease Control and Prevention.

\section{Author details}

'Guangdong Provincial Institute of Biological Products and Materia Medica, Guangzhou, Guangdong, China. ${ }^{2}$ Guangdong Provincial Centre for Disease Control and Prevention, Guangzhou, Guangdong, China. ${ }^{3}$ Office of Disease Control and Emergency Response, Chinese Center for Disease Control and Prevention, Beijing, China. ${ }^{4}$ China-US Collaborative Program on Emerging and Re-emerging Infectious Diseases, U.S. Center for Disease Control and Prevention, Beijing, China. ${ }^{5} \mathrm{Global}$ Disease Detection Branch, Division of Global Health Protection, Center for Global Health, U.S. Centers for Disease Control and Prevention, Atlanta, GA, USA.
Received: 18 September 2014 Accepted: 27 January 2015

Published online: 12 February 2015

\section{References}

1. Galanis E, Lo Fo Wong DM, Patrick ME, Binsztein N, Cieslik A, Chalermchikit T, et al. Web-based surveillance and global Salmonella distribution, 2000-2002. Emerg Infect Dis. 2006;12(3):381-8.

2. Linam WM, Gerber MA. Changing epidemiology and prevention of Salmonella infections. Pediatr Infect Dis J. 2007;26(8):747-8.

3. Majowicz SE, Musto J, Scallan E, Angulo FJ, Kirk M, O'Brien SJ, et al. The global burden of nontyphoidal Salmonella gastroenteritis. Clin Infect Dis. 2010;50(6):882-9.

4. Scallan E, Hoekstra RM, Angulo FJ, Tauxe RV, Widdowson MA, Roy SL, et al. Foodborne illness acquired in the United States-major pathogens. Emerg Infect Dis. 2011;17(1):7-15.

5. Scallan E, Mahon BE, Hoekstra RM, Griffin PM. Estimates of illnesses, hospitalizations and deaths caused by major bacterial enteric pathogens in young children in the United States. Pediatr Infect Dis J. 2013;32(3):217-21.

6. Ran L, Wu S, Gao Y, Zhang X, Feng Z, Wang Z, et al. Laboratory-based surveillance of nontyphoidal Salmonella infections in China. Foodborne Pathog Dis. 2011;8(8):921-7.

7. Feasey NA, Dougan G, Kingsley RA, Heyderman RS, Gordon MA. Invasive non-typhoidal Salmonella disease: an emerging and neglected tropical disease in Africa. Lancet. 2012;379(9835):2489-99.

8. Sjölund-Karlsson M, Folster JP, Pecic G, Joyce K, Medalla F, Rickert R, et al. Emergence of plasmid-mediated quinolone resistance among non-Typhi Salmonella enterica isolates from humans in the United States. Antimicrob Agents Chemother. 2009;53(5):2142-21444.

9. Sjölund-Karlsson M, Rickert R, Matar C, Pecic G, Howie RL, Joyce K, et al. Salmonella isolates with decreased susceptibility to extended-spectrum cephalosporins in the United States. Foodborne Pathog Dis. 2010;7(12):1503-9.

10. Crump JA, Kretsinger K, Gay K, Hoekstra RM, Vugia DJ, Hurd S, et al. Clinical response and outcome of infection with Salmonella enterica serotype Typhi with decreased susceptibility to fluoroquinolones: a United States foodnet multicenter retrospective cohort study. Antimicrob Agents Chemother. 2008;52(4):1278-84.

11. Kehrenberg C, de Jong A, Friederichs S, Cloeckaert A, Schwarz S. Molecular mechanisms of decreased susceptibility to fluoroquinolones in avian Salmonella serovars and their mutants selected during the determination of mutant prevention concentrations. J Antimicrob Chemother. 2007;59(5):886-92.

12. Lee HY, Su LH, Tsai MH, Kim SW, Chang HH, Jung SI, et al. High rate of reduced susceptibility to ciprofloxacin and ceftriaxone among nontyphoid Salmonella clinical isolates in Asia. Antimicrob Agents Chemother. 2009;53(6):2696-9.

13. Casin I, Breuil J, Darchis JP, Guelpa C, Collatz E. Fluoroquinolone resistance linked to GyrA, GyrB, and ParC mutations in Salmonella enterica typhimurium isolates in humans. Emerg Infect Dis. 2003;9(11):1455-7.

14. Koirala KD, Thanh DP, Thapa SD, Arjyal A, Karkey A, Dongol S, et al. Highly resistant Salmonella enterica serovar Typhi with a novel gyrA mutation raises questions about the long-term efficacy of older fluoroquinolones for treating typhoid fever. Antimicrob Agents Chemother. 2012;56(5):2761-2.

15. Nakaya $H$, Yasuhara A, Yoshimura K, Oshihoi Y, Izumiya H, Watanabe $H$. Life-threatening infantile diarrhea from fluoroquinolone-resistant Salmonella enterica typhimurium with mutations in both gyrA and parC. Emerg Infect Dis. 2003;9(2):255-7.

16. Helms M, Ethelberg S, Molbak K. International Salmonella Typhimurium DT104 infections, 1992-2001. Emerg Infect Dis. 2005;11(6):859-67.

17. Su LH, Chiu CH, Chu C, Ou JT. Antimicrobial resistance in nontyphoid Salmonella serotypes: a global challenge. Clin Infect Dis. 2004;39(4):546-51.

18. Feng Z, Li W, Varma JK. Gaps remain in China's ability to detect emerging infectious diseases despite advances since the onset of SARS and avian flu. Health Aff (Millwood). 2011;30(1):127-35.

19. Deng X, Ran L, Wu S, Ke B, He D, Yang X, et al. Laboratory-based surveillance of non-typhoidal Salmonella infections in Guangdong Province, China. Foodborne Pathog Dis. 2012;9(4):305-12.

20. Grimont PAD, Weill FX. Antigenic formulae of the Salmonella serovars. Paris, France: WHO Collaborating Centre for Reference and Research on Salmonella, Institut Pasteur; 2007.

21. Cockerill F. Clinical, Institute LS. Performance Standards for Antimicrobial Susceptibility Testing: Twenty-first Informational Supplement: Clinical and Laboratory Standards Institute. 2011 
22. Varma JK, Greene KD, Ovitt J, Barrett TJ, Medalla F, Angulo FJ. Hospitalization and antimicrobial resistance in Salmonella outbreaks, 1984-2002. Emerg Infect Dis. 2005;11(6):943-6.

23. Huang Q, Wang X, Lu L. The effectiveness of food-borne diseases training among clinicians in Guangdong, China. Food Contr. 2013;33(1):268-73.

24. Bryce J, Boschi-Pinto C, Shibuya K, Black RE. WHO estimates of the causes of death in children. Lancet. 2005;365(9465):1147-52.

25. Olsen SJ, Bishop R, Brenner FW, Roels TH, Bean N, Tauxe RV, et al. The changing epidemiology of Salmonella: trends in serotypes isolated from humans in the United States, 1987-1997. J Infect Dis. 2001;183(5):753-61.

26. Bassal R, Reisfeld A, Andorn N, Yishai R, Nissan I, Agmon V, et al. Recent trends in the epidemiology of non-typhoidal Salmonella in Israel, 1999-2009. Epidemiol Infect. 2012;140(8):1446-53.

27. Hendriksen RS, Bangtrakulnonth A, Pulsrikarn C, Pornruangwong S, Noppornphan $\mathrm{G}$, Emborg HD, et al. Risk factors and epidemiology of the ten most common Salmonella serovars from patients in Thailand: 2002-2007. Foodborne Pathog Dis. 2009;6(8):1009-19.

28. Hopkins KL, Kirchner M, Guerra B, Granier SA, Lucarelli C, Porrero MC, et al. Multiresistant Salmonella enterica serovar 4,[5],12:i:- in Europe: a new pandemic strain? Euro Surveill. 2010;15(22):19580.

29. Switt Al, Soyer Y, Warnick LD, Wiedmann M. Emergence, distribution, and molecular and phenotypic characteristics of Salmonella enterica serotype 4,5,12:i:-. Foodborne Pathog Dis. 2009;6(4):407-15.

30. Benacer D, Thong KL, Watanabe H, Puthucheary SD. Characterization of drug resistant Salmonella enterica serotype Typhimurium by antibiograms, plasmids, integrons, resistance genes and PFGE. J Microbiol Biotechnol. 2010;20(6):1042-52.

31. Crump JA, Medalla FM, Joyce KW, Krueger AL, Hoekstra RM, Whichard JM, et al. Antimicrobial resistance among invasive nontyphoidal Salmonella enterica isolates in the United States: National Antimicrobial Resistance Monitoring System, 1996 to 2007. Antimicrob Agents Chemother. 2011; 55(3):1148-54

32. Guerrant RL, Van Gilder T, Steiner TS, Thielman NM, Slutsker L, Tauxe RV et al. Practice guidelines for the management of infectious diarrhea. Clin Infect Dis. 2001:32(3):331-51.

33. Onwuezobe IA, Oshun PO, Odigwe CC. Antimicrobials for treating symptomatic non-typhoidal Salmonella infection. Cochrane Database Syst Rev. 2012;11:CD001167.

34. Christopher A, Mshana SE, Kidenya BR, Hokororo A, Morona D. Bacteremia and resistant gram-negative pathogens among under-fives in Tanzania. Ital J Pediatr. 2013;39:27.

35. Cockerill F, Clinical, Institute LS. Performance Standards for Antimicrobial Susceptibility Testing: Twenty-first Informational Supplement. In: Clinical and Laboratory Standards Institute. 2011.

\section{Submit your next manuscript to BioMed Central and take full advantage of:}

- Convenient online submission

- Thorough peer review

- No space constraints or color figure charges

- Immediate publication on acceptance

- Inclusion in PubMed, CAS, Scopus and Google Scholar

- Research which is freely available for redistribution 